\title{
Neodymium-doped nanoparticles for infrared fluorescence bioimaging: The role of the host
}

\author{
Blanca del Rosal, ${ }^{1}$ Alberto Pérez-Delgado, ${ }^{1}$ Małgorzata Misiak, ${ }^{2,3}$ Artur Bednarkiewicz, ${ }^{2,3}$ \\ Alexander S. Vanetsev, ${ }^{4}$ Yurii Orlovskii, ${ }^{4,5}$ Dragana J. Jovanović, ${ }^{6}$ Miroslav D. Dramićanin, ${ }^{6}$ \\ Ueslen Rocha, ${ }^{1}$ K. Upendra Kumar, ${ }^{7}$ Carlos Jacinto, ${ }^{7}$ Elizabeth Navarro, ${ }^{8}$ \\ Emma Martín Rodríguez, ${ }^{1}$ Marco Pedroni, ${ }^{9}$ Adolfo Speghini, ${ }^{9}$ Gustavo A. Hirata, ${ }^{10}$ \\ I. R. Martín, ${ }^{11}$ and Daniel Jaque ${ }^{1, a)}$ \\ ${ }^{1}$ Fluorescence Imaging Group, Dpto. de Física de Materiales, Facultad de Ciencias, \\ Universidad Autónoma de Madrid, Campus de Cantoblanco, Madrid 28049, Spain \\ ${ }^{2}$ Wroclaw Research Centre EIT+, ul. Stabłowicka 147, 54-066 Wroctaw, Poland \\ ${ }^{3}$ Institute of Physics, University of Tartu, 14c Ravila Str., 50411 Tartu, Estonia \\ ${ }_{5}^{4}$ Institute of Low Temperature and Structure Research, PAS, ul. Okólna 2, 50-422 Wroctaw, Poland \\ ${ }^{5}$ Prokhorov General Physics Institute RAS, 38 Vavilov Str., 119991 Moscow, Russia \\ ${ }^{6}$ Vinča Institute of Nuclear Sciences, University of Belgrade, P.O. Box 522, Belgrade 11001, Serbia \\ ${ }^{7}$ Grupo de Fotônica e Fluidos Complexos, Instituto de Física, Universidade Federal de Alagoas, \\ 57072-900 Maceió-AL, Brazil \\ ${ }^{8}$ Depto. de Química, Eco Catálisis, UAM-Iztapalapa, Sn. Rafael Atlixco 186, México 09340, D.F, Mexico \\ ${ }^{9}$ Nanomaterials Research Group, Dipartimento di Biotecnologie, Università di Verona and INSTM, \\ UdR Verona, Strada Le Grazie 15, Verona, Italy \\ ${ }^{10}$ Centro de Nanociencias y Nanotecnología-UNAM, Ensenada, B.C., México 22860, Mexico \\ ${ }^{11}$ Departamento de Física, Instituto de Materiales y Nanotecnología (IMN), Universidad de La Laguna, \\ 38206 San Cristóbal de La Laguna, Santa Cruz de Tenerife, Spain
}

(Received 27 July 2015; accepted 27 September 2015; published online 13 October 2015)

The spectroscopic properties of different infrared-emitting neodymium-doped nanoparticles $\left(\mathrm{LaF}_{3}: \mathrm{Nd}^{3+}, \mathrm{SrF}_{2}: \mathrm{Nd}^{3+}, \mathrm{NaGdF}_{4}: \mathrm{Nd}^{3+}, \mathrm{NaYF}_{4}: \mathrm{Nd}^{3+}, \mathrm{KYF}_{4}: \mathrm{Nd}^{3+}, \mathrm{GdVO}_{4}: \mathrm{Nd}^{3+}\right.$, and $\left.\mathrm{Nd}: \mathrm{YAG}\right)$ have been systematically analyzed. A comparison of the spectral shapes of both emission and absorption spectra is presented, from which the relevant role played by the host matrix is evidenced. The lack of a "universal" optimum system for infrared bioimaging is discussed, as the specific bioimaging application and the experimental setup for infrared imaging determine the neodymiumdoped nanoparticle to be preferentially used in each case. (C) 2015 AIP Publishing LLC.

[http://dx.doi.org/10.1063/1.4932669]

\section{INTRODUCTION}

Fluorescence-based techniques, such as flow cytometry or fluorescence microscopy, are nowadays essential tools in biomedical research. ${ }^{1-3}$ Moreover, fluorescence imaging has become a promising technique for in vivo sensing, diagnostics, and targeting. ${ }^{4,5}$ Fluorescent labels have even been used to provide in vivo contrast during surgery, enabling, for instance, the detection of sentinel lymph nodes, and the complete resection of cancer tumors. ${ }^{6-8}$ Fluorescence-assisted techniques have also been successfully applied to cardiovascular surgery procedures, organ transplantation, as well as controlled photothermal treatments. ${ }^{9-11}$

All of these techniques require the use of optical probes that could act as contrast agents. Molecular probes, such as fluorescent proteins and dyes, have been extensively used for this purpose and some of them have been approved for clinical use. ${ }^{12-14}$ Although they exhibit good brightness owing to high emission quantum yield, these probes present some drawbacks, including a high susceptibility to photobleaching or requirement to use short wavelength photoexcitation, which has motivated scientists to search for alternative

\footnotetext{
a) Author to whom correspondence should be addressed. Electronic mail: daniel.jaque@uam.es
}

optical probes. One of the most promising alternatives is based on luminescent nanoparticles (LNPs). LNPs display a number of features that make them interesting for in vivo imaging, such as tunable pharmacokinetics (blood half-life and clearance mode), resistance to photobleaching and large surface to volume ratios (so that multiple targeting groups and therapeutic agents can be conjugated to them). ${ }^{15,16}$

A great variety of LNPs have been applied in biomedical research, not only for imaging but also for other purposes including drug delivery and in vitro and in vivo photothermal therapies. ${ }^{17}$ Quantum dots (QDs), ${ }^{18,19}$ gold NPs,${ }^{20}$ carbonbased NPs (C-NPs) ${ }^{21,22}$ organic NPs, ${ }^{23}$ and rare earth-doped nanocrystals (RENPs) ${ }^{24}$ are among the nanoparticle-based fluorescent probes that have been successfully used in biomedicine.

The spectroscopic properties of these nanosized luminescent systems vary greatly between them, and their excitation and emission wavelengths range from the visible to the infrared. LNPs working in the visible domain have been traditionally used for in vitro imaging using the fluorescence microscopes developed for molecular probes. Nevertheless, when facing in vivo imaging, the penetration depth of light into biological tissues must be taken into account. Choosing appropriate LNPs, whose excitation and emission wavelengths lie in the so-called biological windows (BW), is 
critical to ensure that light attenuation is minimal. These biological windows correspond to infrared spectral ranges (650-950 nm, first biological window, and 1000-1350 nm, second biological window) in which the extinction coefficient of tissues is minimum due to a simultaneous reduction in both tissue scattering and absorption coefficients. ${ }^{25,26}$ Working within BWs allows for overcoming the reduced in vivo penetration lengths achievable by visible-emitting LNPs (hundreds of microns). ${ }^{27}$

Although the number of infrared-emitting fluorescent nanoprobes working in the BWs is reduced compared to that of visible-emitting NPs, different IR-emitting QDs, C-NPs, and RENPs have been synthesized and studied for deep tissue in vivo imaging purposes. ${ }^{28-30}$ Among all these IR-emitting systems, neodymium-doped NPs (Nd:NPs) arise as exceptional candidates for in vivo fluorescence imaging due to their unique combination of properties. First of all, Nd:NPs can be optically excited with $808 \mathrm{~nm}$ laser radiation, which is a nonheating, non-damaging wavelength that can be provided by a commercially available and cost-effective laser diode. ${ }^{31}$ Moreover, neodymium ions present emission bands in the first and second biological windows (890, 1060, and $1300 \mathrm{~nm})$, all of which can be used for in vivo imaging purposes. ${ }^{32}$

Figure 1 shows, as a representative example, the in vivo infrared fluorescence images reported up to now based on $\mathrm{Nd}$ :NPs. The first demonstration of the capacity of Nd:NPs for in vivo imaging was demonstrated by Prasad and coworkers in 2012. ${ }^{33}$ In this pioneering work, authors performed a subcutaneous injection of $\mathrm{NaGdF}_{4}: \mathrm{Nd}^{3+} \mathrm{NPs}$ into a living mouse (Figure 1(a)). A fluorescence image of this subcutaneous injection was obtained under $808 \mathrm{~nm}$ optical excitation by recording the $900 \mathrm{~nm}$ signal (corresponding to the ${ }^{4} \mathrm{~F}_{3 / 2} \rightarrow{ }^{4} \mathrm{I}_{9 / 2}$ transition of $\mathrm{Nd}^{3+}$ ions). Two years later, Rocha et al. reported the first infrared deep-tissue in vivo image of a mouse after intravenous injection of $\mathrm{LaF}_{3}: \mathrm{Nd}^{3+}$ NPs (Figure 1(b)). ${ }^{34,35}$ In this case, a preferential accumulation of the Nd:NPs in the liver and the spleen was evidenced by recording (with a Si-based camera) the spatial distribution of the intense $1060 \mathrm{~nm}$ fluorescence (corresponding to the ${ }^{4} \mathrm{~F}_{3 / 2} \rightarrow{ }^{4} \mathrm{I}_{11 / 2}$ transition) generated under $808 \mathrm{~nm}$ optical excitation. More recently, Villa et al. used $\mathrm{SrF}_{2}: \mathrm{Nd}^{3+}$ nanoparticles for autofluorescence-free deep tissue fluorescence

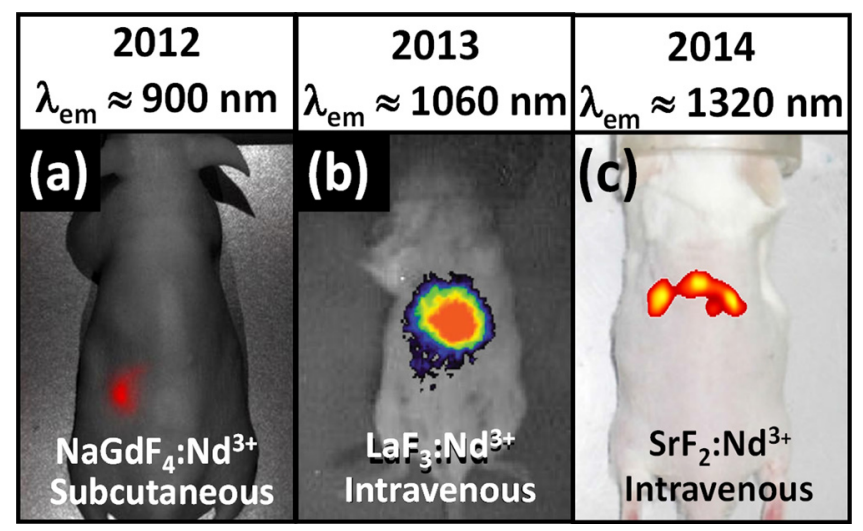

FIG. 1. In vivo fluorescence images obtained with Nd:NPs. The particular system used, imaging wavelength, and injection method are indicated in each case. Images extracted from Refs. 33, 34, and 36. imaging of a living mouse after intravenous injection of $\mathrm{SrF}_{2}: \mathrm{Nd}^{3+}$ nanoparticles. ${ }^{36}$ In this case, autofluorescencefree evidence of nanoparticle accumulation at both liver and spleen was obtained by recording the $1320 \mathrm{~nm}$ fluorescence $\left({ }^{4} \mathrm{~F}_{3 / 2} \rightarrow{ }^{4} \mathrm{I}_{13 / 2}\right.$ transition) with an InGaAs camera (see Figure 1(c)).

Only these three $\mathrm{Nd}: \mathrm{NPs}\left(\mathrm{LaF}_{3}: \mathrm{Nd}^{3+}, \mathrm{SrF}_{2}: \mathrm{Nd}^{3+}\right.$, and $\mathrm{NaGdF}_{4}: \mathrm{Nd}^{3+}$ ) have been successfully demonstrated as in vivo fluorescent probes as, to the best of our knowledge, no literature is available for experimental demonstration of in vivo fluorescence imaging using other $\mathrm{Nd}^{3+}$ doped systems.

The promising results obtained with these NPs for in vivo imaging, displayed in Figure 1, have increased the interest in $\mathrm{Nd}$ :NPs, bringing about reports on the synthesis and characterization of a variety of nanometric systems doped with $\mathrm{Nd}^{3+}$. However, the choice of the most appropriate system (i.e., matrix for the $\mathrm{Nd}^{3+}$ ions) will depend on the specific application and characteristics of the imaging setup (excitation wavelength, detection system, and absence/presence of infrared autofluorescence among others). For this purpose, a comparative analysis of the luminescence properties of different Nd:NPs, such as the position of the different emission peaks, bandwidths, and branching ratios, is required. However, despite of its interest, such a comparative study has not been performed yet.

The aim of this work is to provide a systematic comparison of the optical properties of different Nd:NPs. In this work, we have systematically investigated the basic optical properties of up to seven different Nd:NPs systems. This work constitutes a comparative study of the three Nd:NPs that have already been used for in vivo imaging purposes along with four other $\mathrm{Nd}^{3+}$ doped systems $\left(\mathrm{NaYF}_{4}: \mathrm{Nd}^{3+}\right.$, $\mathrm{KYF}_{4}: \mathrm{Nd}^{3+}, \mathrm{GdVO}_{4}: \mathrm{Nd}^{3+}$, and $\mathrm{Y}_{3} \mathrm{Al}_{5} \mathrm{O}_{12}: \mathrm{Nd}^{3+}$-hereafter Nd:YAG-) whose synthesis, basic characterization, and potential use as infrared biolabels have been reported and proposed. ${ }^{37-40}$ The relevant role played by host in determining the fluorescent properties of Nd:NPs is discussed and, based on the comparative spectroscopic characterization, the ability of the different systems for in vivo imaging experiments will be discussed.

\section{EXPERIMENTAL SECTION}

For all the spectroscopic measurements included in this work, an aqueous dispersion of each of the different Nd:NPs was prepared at the minimum particle concentration that allowed for a high signal-to noise detection of the fluorescence signal (typically, between $0.1 \%$ and $0.6 \%$ in mass). Figure 2 shows optical images of cuvettes containing the aqueous dispersions used in this work, along with TEM images of all the studied NPs. The average size of each system is also represented in Figure 2 (bottom right). Note that all the Nd:NPs used in this work present average sizes in the $10-30 \mathrm{~nm}$ range except for the Nd:YAG and $\mathrm{GdVO}_{4}: \mathrm{Nd}^{3+}$ NPs which, because of their synthesis methods, showed average sizes of 80 and $5 \mathrm{~nm}$, respectively.

\section{A. Nanoparticle synthesis}

Different synthesis procedures were employed in the fabrication of the Nd:NPs studied in this work. Some of 


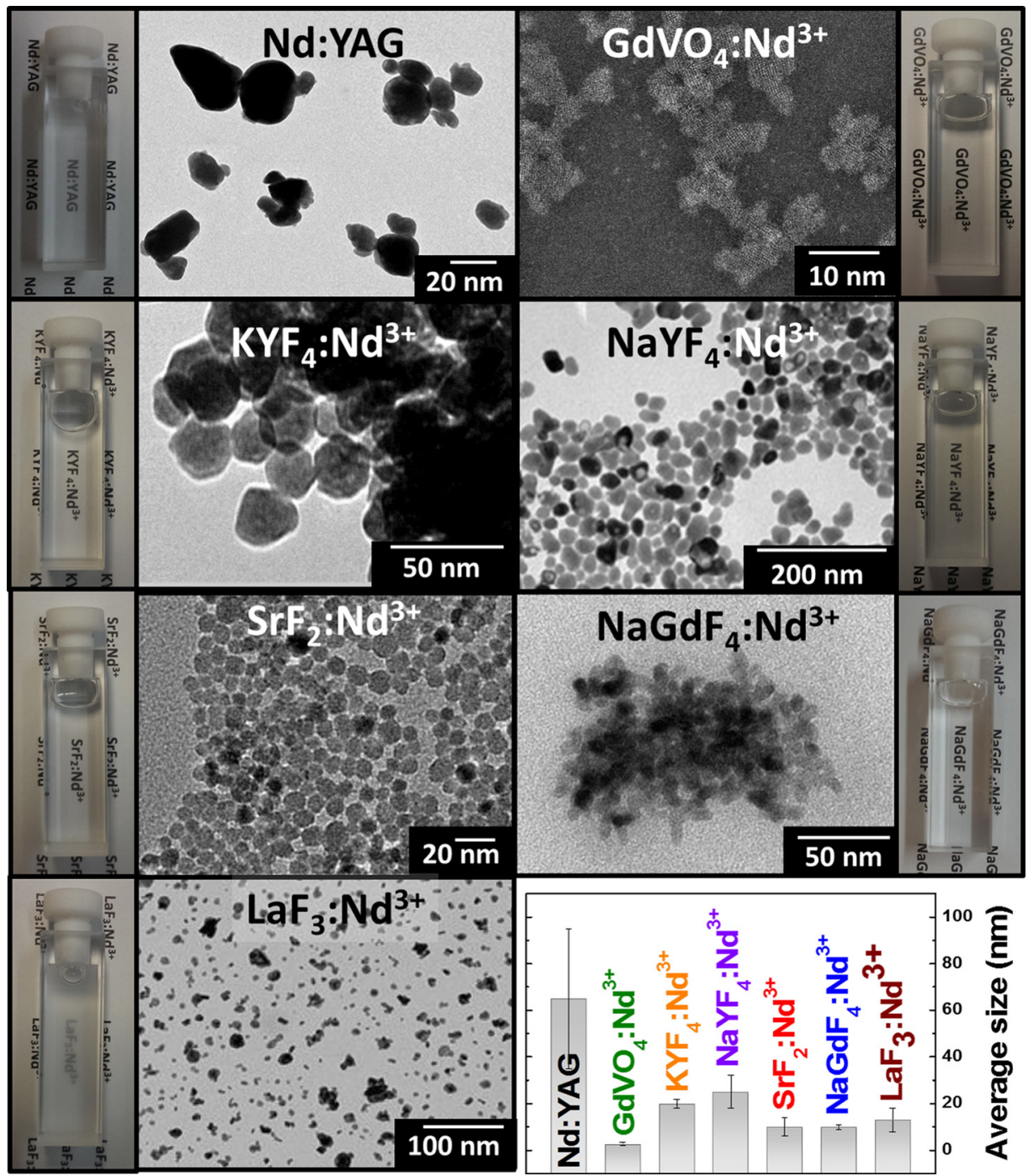

FIG. 2. TEM images of the different Nd:NPs used in this work. Their average size is included at the bottom right of the figure. Optical images of cuvettes containing the aqueous dispersions of NPs are also included. them are thoroughly described in the previous reports, so they will be very briefly described here.

Nd:YAG NPs were fabricated using a combustion synthesis method as is described in detail by Benayas et al. ${ }^{40}$ Briefly, commercial precursors were mixed without further purification in a reaction beaker with deionized water and a fuel for the combustion, stirred and heated to $530{ }^{\circ} \mathrm{C}$ for 3-5 min. The product was crushed with a mortar and pestle and annealed at $1200^{\circ} \mathrm{C}$ before going through a multistep sonication process in order to break possible agglomerates.

For the synthesis of $\mathrm{GdVO}_{4}: \mathrm{Nd}^{3+} \mathrm{NPs}$, all chemicals (gadolinium(III)-nitrate hexahydrate, $\mathrm{Gd}\left(\mathrm{NO}_{3}\right)_{3} \times 6 \mathrm{H}_{2} \mathrm{O}$ (99.9\%, Alfa Aesar), $\mathrm{Nd}\left(\mathrm{NO}_{3}\right)_{3} \times 6 \mathrm{H}_{2} \mathrm{O}$ (99.9\%, Alfa Aesar), ammonium-vanadium oxide, $\mathrm{NH}_{4} \mathrm{VO}_{3}$ (min. 99.0\%, Alfa Aesar), and sodium-hydroxide, $\mathrm{NaOH}$ (min. 99\%, Moss Hemos)) were used as received. 0.05 $\mathrm{M}$ solution of sodium citrate $(15 \mathrm{ml})$ were added dropwise to the $0.05 \mathrm{M}$ water solution of $\mathrm{Gd}\left(\mathrm{NO}_{3}\right)_{3}$ and $\mathrm{Nd}\left(\mathrm{NO}_{3}\right)_{3}(20 \mathrm{ml})$ in stoichiometric concentration ratio at room temperature. The lanthanide citrate complex precipitate was formed and was then completely dissolved by dropwise addition of $0.05 \mathrm{M} \mathrm{NH}_{4} \mathrm{VO}_{3}$ ( $15 \mathrm{ml}$, dissolved in $0.15 \mathrm{M} \mathrm{NaOH}$ ). The clear and bluish solution $\left(\mathrm{pH} \sim 8\right.$ ) was subsequently heated at $60^{\circ} \mathrm{C}$ for $60 \mathrm{~min}$. Finally, the colloidal solution was cooled down to room temperature. Slow growth of the particles was achieved after dialysis against water until $\mathrm{pH}=7$ was reached.

As starting compounds for the preparation of the $\mathrm{KYF}_{4}: \mathrm{Nd}^{3+} \mathrm{NPs}$ nanoparticles, we used $\mathrm{Y}\left(\mathrm{NO}_{3}\right)_{3} \cdot 4 \mathrm{H}_{2} \mathrm{O}$ (Aldrich, $99.999 \%$ purity), $\mathrm{Nd}\left(\mathrm{NO}_{3}\right)_{3} \cdot 5 \mathrm{H}_{2} \mathrm{O}$ (Aldrich, $99.999 \%$ purity), KF (Aldrich, $>99 \%$ purity. For the synthesis of the cubic $\mathrm{Nd}^{3+}: \mathrm{KYF}_{4}$ nanoparticles, we prepared solutions of $\mathrm{Y}\left(\mathrm{NO}_{3}\right)_{3} \cdot 4 \mathrm{H}_{2} \mathrm{O}$ (4.950 mmols or $\left.4.995 \mathrm{mmols}\right)$ and $\mathrm{Nd}\left(\mathrm{NO}_{3}\right)_{3} \cdot 5 \mathrm{H}_{2} \mathrm{O}(0.050$ or $0.005 \mathrm{mmol}$, respectively) in a $10 \mathrm{ml}$ of deionized water, as well as the solution of $50 \mathrm{mmol}$ of $\mathrm{KF}$ in a $30 \mathrm{ml}$ of deionized water. Thereafter, the solutions of nitrates were added dropwise to the solution of fluoride under vigorous stirring and left stirring for $15 \mathrm{~min}$. The freshly precipitated gel was diluted in the mother solution with $10 \mathrm{ml}$ of deionized water. In order to increase the dispersibility of the resulting nanoparticles, the Emuksol-268 (NIOPIK) biocompatible poloxamer was added to the rareearth nitrates solution mixture before the gel precipitation. ${ }^{38}$ The obtained gel was transferred into the $100 \mathrm{ml}$ teflon autoclave and exposed to microwave-hydrothermal (MW-HT) treatment $\left(200^{\circ} \mathrm{C}, 4 \mathrm{~h}\right)$ using Berghof Speedwave-4 laboratory device $(2.45 \mathrm{GHz}, 1 \mathrm{~kW}$ maximum output power). After the treatment, the sample was centrifuged, washed several times with deionized water, and air-dried at $100^{\circ} \mathrm{C}$ for $2 \mathrm{~h}$. 
$\alpha-\mathrm{NaYF}_{4}: \mathrm{Nd}^{3+} \mathrm{NPs}$ were synthesized via a thermal decomposition method as described in the literature. ${ }^{37}$ Briefly, the reaction was carried out in a mixed solvent consisting of oleic acid (OA) and 1-octadecene added to the flask containing previously prepared dried trifluoroacetate precursors. The mixture was stirred for about $40 \mathrm{~min}$ under vacuum at temperature slightly above $110^{\circ} \mathrm{C}$ and then heated to $300^{\circ} \mathrm{C}$ and stirred under nitrogen for $1 \mathrm{~h}$. After cooling the mixture to room temperature, the nanocrystals were precipitated by a mixture of n-hexane and acetone and collected by centrifugation of the suspension. Water-dispersible nanoparticles were obtained by a ligand exchange procedure from oleic acid to 3-mercaptopropionic acid.

$\mathrm{SrF}_{2}: \mathrm{Nd}^{3+} \mathrm{NPs}$ preparation has been previously described by Pedroni et al. ${ }^{41}$ Briefly, stoichiometric amounts of the lanthanide chlorides and strontium chlorides were dissolved in $7 \mathrm{ml}$ of de-ionized water (total metal amount of $3.5 \mathrm{mmol}$ ). To this solution, $20 \mathrm{ml}$ of a $1 \mathrm{M}$ solution of potassium citrate were added dropwise under vigorous stirring for a few minutes. Then, $8.75 \mathrm{mmol}$ of ammonium fluoride was added to the previous solution. The resultant clear solution was heated in a $50 \mathrm{ml}$ stainless steel Teflon lined digestion pressure vessel at $190^{\circ} \mathrm{C}$ for $6 \mathrm{~h}$. After washing with acetone and drying at room temperature, the obtained NPs were dispersed in water.

$\mathrm{NaGdF}_{4}: \mathrm{Nd}^{3+} \mathrm{NPs}$ were synthesized by adapting the solvothermal method reported by Wang et al. described in previous works. ${ }^{42}$ For the synthesis of the rare earth stearate precursor, $\mathrm{Gd}_{2} \mathrm{O}_{3}(99.99 \%, 186 \mathrm{mg}, 0.51 \mathrm{mmol}), 0.0558 \mathrm{~g}$ and $\mathrm{Nd}_{2} \mathrm{O}_{3}(99.99 \%, 5.6 \mathrm{mg} 0.02 \mathrm{mmol})$ were dissolved in nitric acid $(10 \mathrm{ml})$ by heating and stirring for $60 \mathrm{~min}$. The nitrate intermediate was subsequently obtained by evaporation of the solvent. The prepared nitrate powder and stearic acid $(240 \mathrm{mg}, 0.84 \mathrm{mmol})$ were dissolved in hot ethanol $(25 \mathrm{ml})$ under stirring to form a homogeneous solution (solution A). Subsequently, another distilled water solution ( $3 \mathrm{ml}$ solvent) containing $\mathrm{NaOH}$ ( $224 \mathrm{mg}, 5.6 \mathrm{mmol}$ ) was added into solution $\mathrm{A}$ and stirred for $30 \mathrm{~min}$. The resulting solution was refluxed at $78^{\circ} \mathrm{C}$ for another $30 \mathrm{~min}$. Precipitates from the reaction mixture were centrifuged and washed twice with ethanol. The stearate precursor was obtained after the precipitates were dried at $60^{\circ} \mathrm{C}$ for $12 \mathrm{~h}$, as a white powder. In the second part of the synthesis, $0.432 \mathrm{~g}$ of the precursor $(432 \mathrm{mg})$ and $0.082 \mathrm{~g}$ of $\mathrm{NaF}(82 \mathrm{mg}, 1.95 \mathrm{mmol})$ were added to a mixture of distilled water $(7 \mathrm{ml})$, ethanol $(7 \mathrm{ml})$ and $2 \mathrm{ml}$ of oleic acid $(2 \mathrm{ml}, 6.34 \mathrm{mmol})$ while stirring about $10 \mathrm{~min}$ to form a homogeneous solution. Then the mixture was transferred to a $37 \mathrm{ml}$ Teflon-lined autoclave and solvothermally treated at $180^{\circ} \mathrm{C}$ for $48 \mathrm{~h}$. After the autoclave cooled down to room temperature, the resulting NPs were isolated via centrifugation and washed with ethanol and hexane for four times, respectively, and then dried at $60^{\circ} \mathrm{C}$ for $12 \mathrm{~h}$. To obtain water dispersible $\mathrm{NaGdF}_{4}: \mathrm{Nd}^{3+} \mathrm{NPs}$, an exchange of the oleate molecules capping their surface with trisodium citrate was carried out. Initially, $60 \mathrm{mg}$ of the hydrophobic nanoparticles were dispersed in hexane $(5 \mathrm{ml})$. After that, $0.2 \mathrm{M}$ trisodium citrate buffer $(5 \mathrm{ml}$, adjusted to $\mathrm{pH} 4$ using concentrated $\mathrm{HCl}$ ) were added to the dispersion. The twophase solution was stirred for $3 \mathrm{~h}$ until a clear separation of the aqueous/organic phases could be observed. The aqueous phase, now containing the nanoparticles, was isolated, and the nanoparticles were precipitated with acetone (1:5 aqueous:organic ratio) and centrifuged.

$\mathrm{LaF}_{3}: \mathrm{Nd}^{3+} \mathrm{NPs}$ were prepared by wet-chemistry method. lanthanum (III) chloride $\left(\mathrm{LaCl}_{3}, 99.9 \%\right)$, neodymium (III) chloride $\left(\mathrm{NdCl}_{3}, 99.9 \%\right)$, and ammonium fluoride $\left(\mathrm{NH}_{4} \mathrm{~F}\right.$, 99.9\%) were purchased from Sigma-Aldrich. All reagents were used directly, without further purification. Typically, $(1-\mathrm{x}) \mathrm{mmol}$ of $\mathrm{LaCl}_{3}, \mathrm{x}$ mmol of $\mathrm{NdCl}_{3}(\mathrm{x}=5 \%, 10 \%$, $15 \%, 20 \%$, and $25 \%$ ) were added to $80 \mathrm{ml}$ of deionized water in a round bottom single neck flask under continuous stirring for $15 \mathrm{~min}$, and heated to $75^{\circ} \mathrm{C}$. Then $3 \mathrm{mmol}$ of $\mathrm{NH}_{4} \mathrm{~F}$ was diluted in $3 \mathrm{ml}$ distilled water and added dropwise to the above mixed chemical solution. The mixture was kept at $75^{\circ} \mathrm{C}$ for $3 \mathrm{~h}$ at ambient pressure under continuous stirring. A white suspension was formed gradually upon stirring. The obtained NPs were collected by centrifugation at $8000 \mathrm{rpm}$ for $7 \mathrm{~min}$. The precipitate was washed with distilled water several times and finally centrifuged at $12000 \mathrm{rpm}$ for $12 \mathrm{~min}$ and dried at $60^{\circ} \mathrm{C}$ at ambient atmosphere for $24 \mathrm{~h}$.

At this point, it is important to remark that the Neodymium content was not the same for all the studied systems, with molar percentages being set to $0.1 \%$ for $\mathrm{KYF}_{4}: \mathrm{Nd}^{3+}, 1 \%$ in the case of $\mathrm{Nd}: \mathrm{YAG}$ and $\mathrm{NaYF}_{4}: \mathrm{Nd}^{3+}$, $2 \%$ for $\mathrm{LaF}_{3}: \mathrm{Nd}^{3+}, 3 \%$ for both $\mathrm{SrF}_{3}: \mathrm{Nd}^{3+}$ and $\mathrm{NaGdF}_{4}: \mathrm{Nd}^{3+}$, and $6 \%$ for $\mathrm{GdVO}_{4}: \mathrm{Nd}^{3+}$. When different $\mathrm{Nd}^{3+}$ doping levels were available for the same system, the one which provided, in each case, the largest emitted intensity was selected. Note that using different $\mathrm{Nd}^{3+}$ doping levels does not subtract any validity to the conclusions extracted from the comparative study. In this work, we have focused on a comparative study of the different spectral shapes of absorption and emission features (spectral shapes) that are, in a first order approximation, independent of the particular $\mathrm{Nd}^{3+}$ doping level being them basically given by the host structural parameters.

\section{B. Luminescence spectroscopy}

All the excitation and emission spectra included in this work were obtained using a $532 \mathrm{~nm}$ pumped continuous wave tunable $(700-1000 \mathrm{~nm})$ Ti:Sapphire laser (Spectra Physics 3900) as excitation source. The excitation light was focused into the colloidal solution containing the Nd:NPs by using a single $5 \mathrm{~cm}$ focal lens, leading to a spot size inside the cuvette close to $1 \mathrm{~mm}$ in diameter. The infrared luminescence generated by colloidal solution was collected and spectrally analyzed by an infrared InGaAs detector coupled to a SPEX $500 \mathrm{M}$ high-resolution spectrometer. The spectral response of the whole detection system was calibrated in the $800-1700 \mathrm{~nm}$ range in order to ensure a proper determination of the branching ratios.

At this point, it should be noted that all along this work we focused our discussion on the excitation spectra of the different colloidal solutions instead of on their absorption spectra so that a comparative discussion between absorption coefficients is not included in this work. This was due to the fact that the absorption spectra obtained in our experimental conditions (using a Perkin Elmer Lambda 1050 UV/Vis 


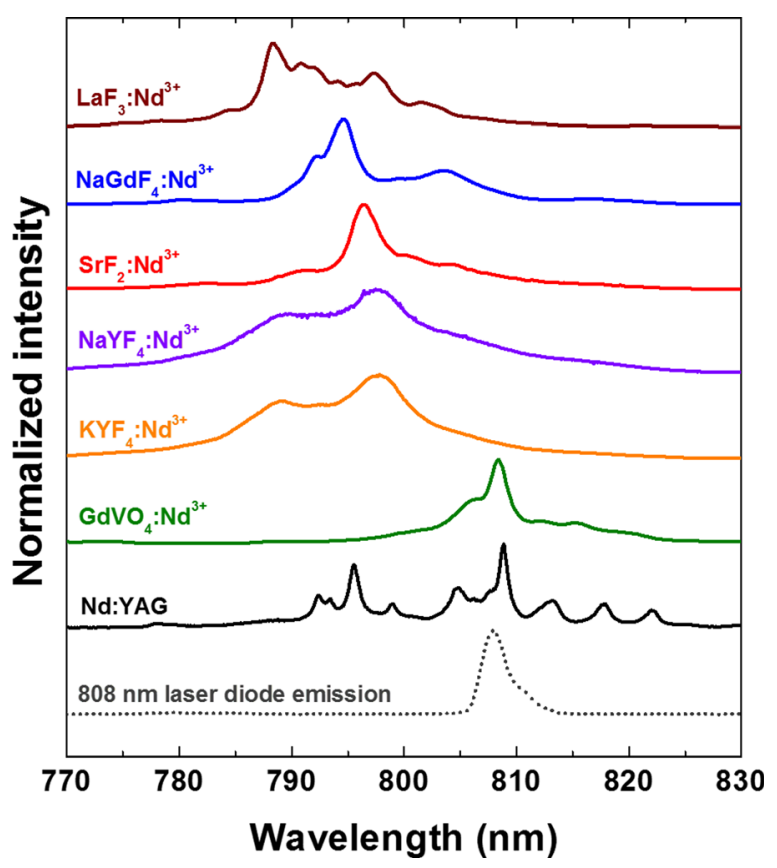

FIG. 3. Normalized excitation spectra in the $770-830 \mathrm{~nm}$ range of all the Nd:NPs studied in this work. In all cases, the emission intensity at $1060 \mathrm{~nm}$ was collected while varying the excitation wavelength. Dashed line corresponds to the emission spectrum of a commercial $808 \mathrm{~nm}$ laser diode.

spectrometer) were not of enough quality to extract from them reliable conclusions. Assessing the absorption spectrum from the extinction spectrum of a colloidal solution of NPs (data provided by double beam spectrometers) requires a proper substraction of the scattering contribution. We realized that, especially for the NPs with larger sizes (Nd:YAG, $\mathrm{KYF}_{4}: \mathrm{Nd}^{3+}$, and $\mathrm{NaYF}_{4}: \mathrm{Nd}^{3+}$ ), the contribution of the scattering was dominant and, consequently, their subtraction to the extinction coefficient lead to a large uncertainty in the finally obtained value of absorption coefficient. Measuring the excitation spectrum constitutes an alternative way to obtain the spectral shape of absorption spectrum without needing any data processing since scattering does not contribute at all. In addition, the acquisition of high signal-tonoise absorption spectra required (in our experimental conditions) the use of large slit apertures resulting in a final spectral resolution of $2 \mathrm{~nm}$. This is much larger than the spectral resolution that could be achieved in the excitation spectra (close to $0.1 \mathrm{~nm}$ in our experimental conditions). Because of all these reasons, we finally decided to base our discussion on the excitation spectra instead of the absorption spectra.

\section{Lifetime measurements}

A Nd:YAG laser operating at $532 \mathrm{~nm}$ providing 5-ns pulses was used to excite the luminescence of the different colloidal solutions of Nd:NPs. Detection was performed with a TRIAX-180 spectrometer coupled with an infrared photomultiplier tube. Transient signals were recorded and averaged using a digital oscilloscope (TEKTRONIX-2430 A).

\section{RESULTS AND DISCUSSION}

\section{A. Optical excitation}

A critical parameter determining the fluorescence performance of Nd:NPs is the spectral dependence of their absorption coefficient. As it is explained in Sec. II B, obtaining accurate, high resolution, absorption spectra of colloidal solutions of Nd:NPs by traditional absorption measurement techniques is sometimes difficult, therefore, we performed a systematic investigation based on the comparison between the different excitation spectra. For samples showing low absorption coefficients (such as colloidal solutions of rare earth doped nanoparticles), the extinction spectrum well reproduces the shape of the absorption coefficient. So, all along this work, the excitation spectra are used to perform a qualitative comparative study of the absorption properties of the different neodymium-doped nanoparticles. For this purpose, the emission intensity of the $1060 \mathrm{~nm}$ fluorescence generated by the different colloidal solutions was monitored while scanning the excitation wavelength in the $770-830 \mathrm{~nm}$ range (corresponding to the ${ }^{4} \mathrm{I}_{9 / 2} \longrightarrow{ }^{4} \mathrm{~F}_{5 / 2}$ transition). The obtained room temperature excitation spectra are shown in Figure 3. From a first inspection of this graph, it can be clearly seen that the commonly used $808 \mathrm{~nm}$ excitation is, surprisingly, far from being the most appropriate wavelength for most of these Nd:NPs under study in this work.

This is evidenced in Table I, in which the maximum excitation and emission wavelengths for the different systems are listed. It can be seen that only $\mathrm{Nd}$ :YAG and $\mathrm{GdVO}_{4}: \mathrm{Nd}^{3+}$ show their excitation maxima close to $808 \mathrm{~nm}$. For the rest of the studied systems, the optimum excitation wavelength falls below $808 \mathrm{~nm}$, in most cases close to $790 \mathrm{~nm}$.

Along with the advantage of being provided by commercially available (cost effective) diodes, from the biological point of view, $808 \mathrm{~nm}$ laser radiation presents additional advantages compared with $790 \mathrm{~nm}$. According to previous studies, laser wavelength is a critical parameter determining photochemical damage at the cellular level. Figure 4

TABLE I. Photoluminescence properties of the Nd:NPs studied in this work.

\begin{tabular}{lcccccc}
\hline \hline Nanoparticle & $\begin{array}{c}\text { Excitation maximum } \\
(\mathrm{nm})\end{array}$ & $\begin{array}{c}\text { Excitation band } \\
\text { FWHM }(\mathrm{nm})\end{array}$ & $\begin{array}{c}\text { Spectral overlap } \\
(\%)\end{array}$ & $\begin{array}{c}\text { Emission maximum } \\
\left({ }^{4} \mathrm{~F}_{3 / 2} \rightarrow{ }^{4} \mathrm{I}_{9 / 2}\right)(\mathrm{nm})\end{array}$ & $\begin{array}{c}\text { Emission maximum } \\
\left({ }^{4} \mathrm{~F}_{3 / 2} \rightarrow{ }^{4} \mathrm{I}_{11 / 2}\right)(\mathrm{nm})\end{array}$ & $\begin{array}{c}\text { Emission maximum } \\
\left({ }^{4} \mathrm{~F}_{3 / 2} \rightarrow{ }^{4} \mathrm{I}_{13 / 2}\right)(\mathrm{nm})\end{array}$ \\
\hline $\mathrm{LaF}_{3}: \mathrm{Nd}^{3+}$ & 788.3 & 5.9 & 6.2 & 863.0 & 1063.6 & 1331.0 \\
$\mathrm{NaGdF}_{4}: \mathrm{Nd}^{3+}$ & 794.5 & 4.4 & 7.7 & 865.2 & 1058.5 & 1318.6 \\
$\mathrm{SrF}_{2}: \mathrm{Nd}^{3+}$ & 796.4 & 3.7 & 8.0 & 867.5 & 1052.2 & 1324.2 \\
$\mathrm{NaYF}_{4}: \mathrm{Nd}^{3+}$ & 797.5 & 9.5 & 4.4 & 868.8 & 1052.2 & 1324.8 \\
$\mathrm{KYF}_{4}: \mathrm{Nd}^{3+}$ & 797.8 & 15.0 & 5.1 & 869.0 & 1063.3 & 1322.2 \\
$\mathrm{GdVO}_{4}: \mathrm{Nd}^{3+}$ & 804.4 & 3.8 & 8.0 & 979.2 & 1064.4 & 1319.0 \\
$\mathrm{Nd}: \mathrm{YAG}$ & 808.9 & 1.2 & 4.7 & 946.0 & \\
\hline \hline
\end{tabular}




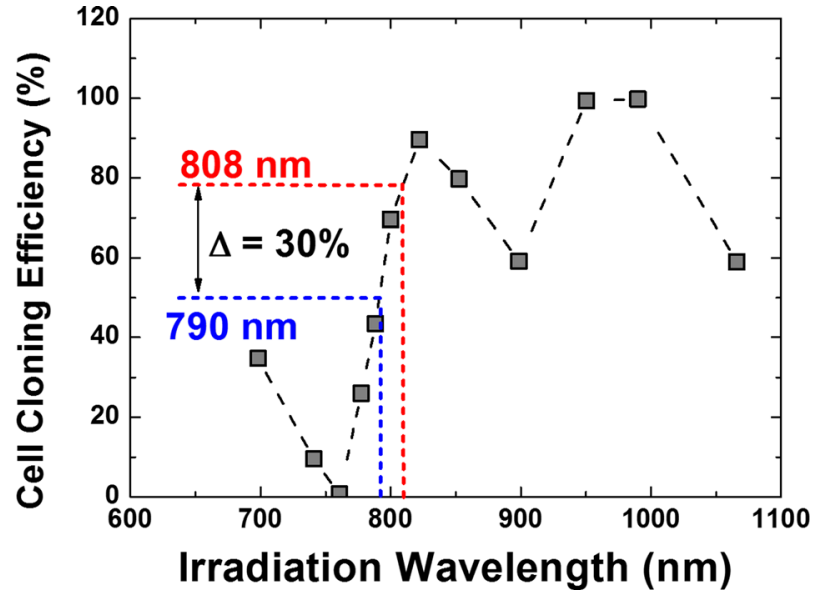

FIG. 4. Cloning efficiency of Chinese hamster ovary (CHO) cells after optical trapping as a function of the trapping wavelength. The duration of the exposure was $3 \mathrm{~min}$ in all cases. Data extracted from Ref. 43.

includes, as an example, the experimental results obtained by Liang et al. who reported on the cloning efficiency of Chinese hamster ovary $(\mathrm{CHO})$ cells after laser irradiation with different wavelengths. ${ }^{43}$ Laser-induced damage can be estimated by the inverse of the relative reduction in cloning efficiency. Cell damage induced by $808 \mathrm{~nm}$ is reduced by about $30 \%$ with respect to that caused by $790 \mathrm{~nm}$ radiation. In addition to the aforementioned work, König and coworkers also found laser radiation close to $790 \mathrm{~nm}(780 \mathrm{~nm}$ in that case) to be highly harmful during two-photon in vitro imaging experiments. ${ }^{44}$ Therefore, the lower laser-induced cell damage at $808 \mathrm{~nm}$ with respect to that at $790 \mathrm{~nm}$ makes $\mathrm{Nd}$ :NPs with excitation maxima close to $808 \mathrm{~nm}$ preferred for bioimaging experiments. Obviously, this conclusion is extracted on the basis of toxicity studies performed in in vitro imaging experiments and its validity has to be confirmed by performing systematic multi-wavelength in vivo studies.

Along with the exact spectral position of the excitation maximum, the excitation/absorption bandwidth has also been calculated in each case from the data included in Figure 3 and is listed in Table I. The excitation bandwidth is a critical parameter for bioimaging experiments using laser diodes as excitation sources. As it occurs with diode-pumped neodymium-doped lasers, the excitation bandwidth determines both the effective absorption of the diode radiation as well as the stability of the fluorescence signal against potential fluctuation in the pump (diode) wavelength. Figure 3 includes, as a dashed line, the emission spectrum corresponding to a typical $808 \mathrm{~nm}$ laser diode. It consists of $\mathrm{a} \approx 3 \mathrm{~nm}$ broad band whose central wavelength is determined by the diode temperature (see Figures 3 and 5). The effective absorption efficiency of diode radiation by Nd:NPs would be given by the integrated spectral overlap between the diode emission and Nd:NPs normalized excitation bands. The effective absorption is low when the excitation band is much narrower than the pumping diode band as, in this case, most pump photons are not absorbed. On the other hand, when the excitation band is much broader than the pumping diode band (due to nonhomogeneous line broadening), only a small fraction of ions are optically excited, resulting in a low effective absorption. If we denote the normalized absorption coefficient by $\propto_{a b s}^{n}(\lambda)$ $\left(\int \propto_{a b s}^{n}(\lambda) d \lambda=1\right)$ and the normalized spectral shape of diode emission by $I_{\text {diode }}^{n}(\lambda)\left(\int I_{\text {diode }}^{n}(\lambda) d \lambda=1\right)$ then the absorption efficiency, $\eta_{a b s}$, is defined as

$$
\eta_{a b s}=\int I_{\text {diode }}^{n}(\lambda) \cdot \propto_{a b s}^{n}(\lambda) \cdot d \lambda .
$$

The spectral overlap between absorption and diode emission spectra for each Nd:NP has been calculated and listed in Table I. To perform those calculations, the laser diode spectrum was spectrally shifted until its maximum emission wavelength matched, in each case, the excitation maximum. In other words, for each case it was considered that a laser diode $(3 \mathrm{~nm}$ spectral width and tuned to the excitation maximum) was being used. As can be observed from Table I, those systems with an excitation bandwidth close to the spectral width of laser diode $\left(\mathrm{GdVO}_{4}: \mathrm{Nd}^{3+}\right.$ and

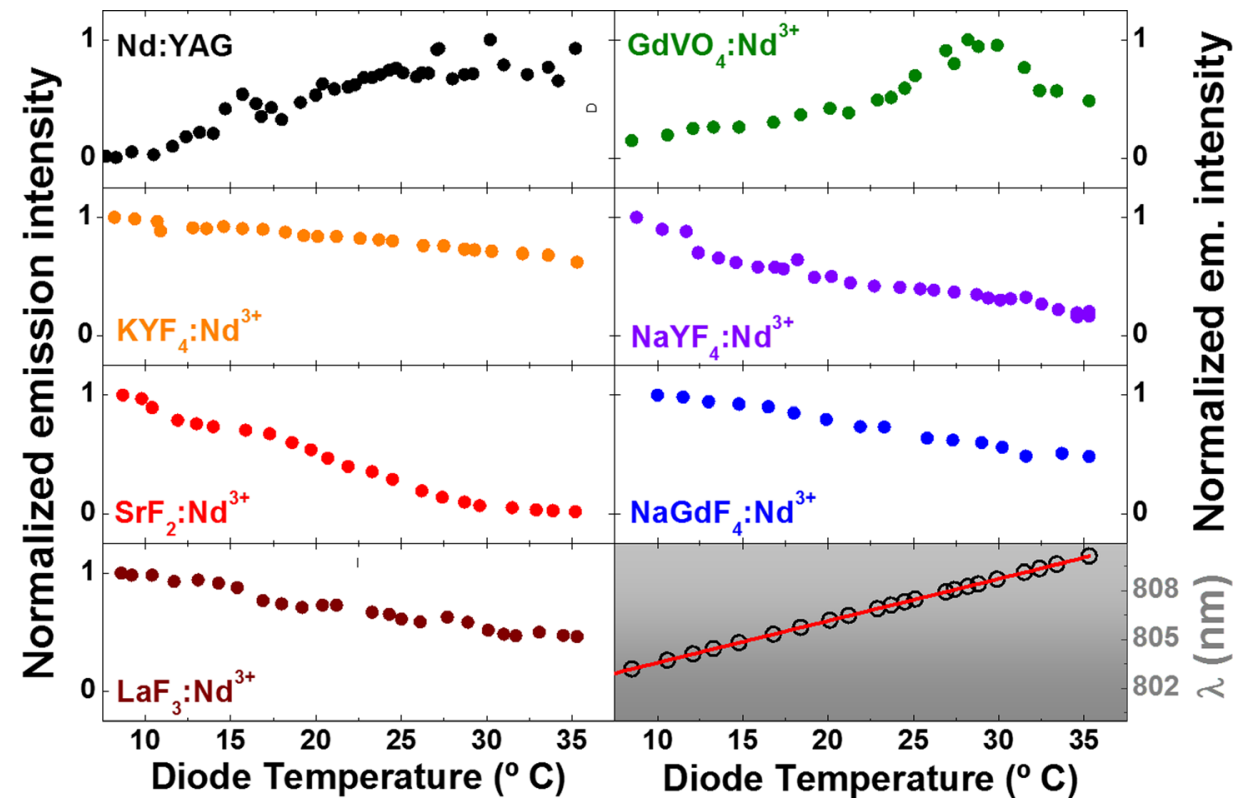

FIG. 5. Overall fluorescence signal in the $850-1700 \mathrm{~nm}$ range of aqueous dispersions containing the Nd:NPs studied in this work under irradiation with an $808 \mathrm{~nm}$ laser diode. The temperature was changed in the $8-36^{\circ} \mathrm{C}$ range, thus producing a change in the wavelength as is indicated in the calibration curve at the bottom right of the figure. 
$\mathrm{SrF}_{2}: \mathrm{Nd}^{3+}$ ) provided the maximum effective absorption of diode radiation (close to $8 \%$ in both cases). Among these two systems, $\mathrm{GdVO}_{4}: \mathrm{Nd}^{3+}$ emerges as especially interesting as in this case, the excitation peak is close to the typical central diode wavelength $(808 \mathrm{~nm})$ so that optimizing the absorption of the pump radiation is possible by tuning the laser emission wavelength by slightly varying its temperature. Typically, the emission wavelength of a laser diode can be spectrally tuned by adjusting the temperature, with wavelength shifts between 0.25 and $0.3 \mathrm{~nm} /{ }^{\circ} \mathrm{C} .{ }^{45}$

As well as determining the absorption efficiency of the excitation radiation, the width of the excitation band determines the magnitude of the fluctuations in the fluorescence intensity caused by the inevitable fluctuations in the diode temperature. Obviously, it would be desirable to work with systems with relatively large excitation bandwidths, as they would be practically unaffected by small changes in the excitation wavelength (i.e., in the diode temperature).

The advantage of showing a broad excitation band was explored herein by performing a systematic study regarding the relevance of diode temperature during infrared fluorescence imaging experiments. The infrared fluorescence of all the colloidal solutions was monitored as the laser diode temperature was changed. Results obtained for all the systems are shown in Figure 5 together with the temperature dependence of the laser wavelength, from which a wavelength shift of $0.26 \mathrm{~nm} /{ }^{\circ} \mathrm{C}$ is obtained for the $808 \mathrm{~nm}$ commercial diode used in this work, well in agreement with the temperature induced thermal drifts typically reported for $808 \mathrm{~nm}$ emitting diodes. $^{45}$

For all systems, the intensity maximum is observed at the shortest excitation wavelength, except for those showing the absorption maximum at around $808 \mathrm{~nm}\left(\mathrm{GdVO}_{4}: \mathrm{Nd}^{3+}\right.$ and Nd:YAG). In the particular case of Nd:YAG NPs, no clear maximum in the "emitted intensity vs diode temperature" curve is observed. This is due to the fact that the spectral width of diode emission spectrum (close to $2 \mathrm{~nm}$ ) is larger than the spectral width of the absorption lines of $\mathrm{Nd}$ :YAG NPs (as low as $1.2 \mathrm{~nm}$ as estimated from the excitation spectrum). Note that, as has been already discussed, data included in Figure 5 reveal $\mathrm{GdVO}_{4}: \mathrm{Nd}^{3+} \mathrm{NPs}$ as especially interesting, because the emitted intensity remains close to the maximum for a diode temperature range as broad as $4{ }^{\circ} \mathrm{C}$. As a consequence, the fluorescence images obtained with these NPs are expected to be virtually unaffected by diode wavelength instabilities.

Thus, from the previous discussion we can conclude that, when choosing a Nd-doped fluorescent probe to work under $808 \mathrm{~nm}$ conventional laser diode excitation, both the excitation maximum and bandwidth should be taken into account. These data are represented as a figure of merit in Figure 6, where the width of the excitation band is represented as a function of the excitation peak for all the nanoparticles studied in this work. The most suitable nanoparticle would be one with a relatively wide excitation band centered at a wavelength of around $808 \mathrm{~nm}$. Thus, an optimized (and not strongly affected by fluctuations in diode temperature) fluorescence signal could be obtained. As shown in the excitation spectra, only Nd:YAG and $\mathrm{GdVO}_{4}: \mathrm{Nd}^{3+} \mathrm{NPs}$ are optimally

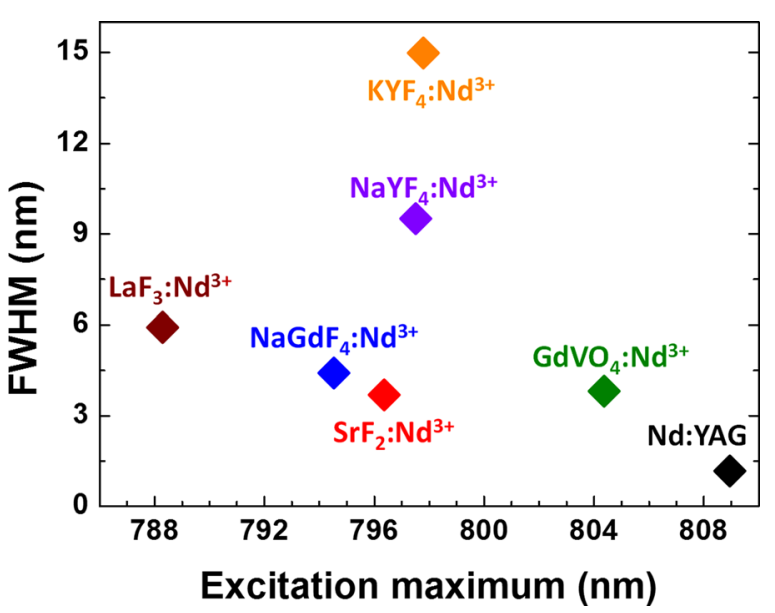

FIG. 6. Figure of merit representing the width and peak wavelength of the excitation band for all the different Nd:NPs studied in this work.

excited with an $808 \mathrm{~nm}$ laser. However, $\mathrm{GdVO}_{4}: \mathrm{Nd}^{3+}$ presents the advantage of having a wider excitation peak $(3.8 \mathrm{~nm})$ due to multi-site structure than $\mathrm{Nd}: \mathrm{YAG}$, with very narrow excitation peaks that result in a high (and undesired) sensitivity to small wavelength fluctuations. Of all the remaining studied systems, whose optimum excitation wavelength lies outside the range achievable with an 808 laser diode, $\mathrm{KYF}_{4}: \mathrm{Nd}^{3+} \mathrm{NPs}$ present the widest excitation peak (see Figure 5) and are the most stable under small wavelength changes (see Figure 4).

\section{B. Infrared luminescence}

The emission spectra of all the colloidal solutions were collected in the $850-1500 \mathrm{~nm}$ range using the Ti:Sapphire laser for optical excitation, tuned to the optimum pump wavelength in each case (as determined from the excitation spectra given in Figure 3). The obtained results are represented in Figure 7.

All the spectra present three distinct emission bands, centered at around $890 \mathrm{~nm}, 1060 \mathrm{~nm}$, and $1320 \mathrm{~nm}$, which correspond to the three detectable transitions $\left({ }^{4} \mathrm{~F}_{3 / 2} \rightarrow{ }^{4} \mathrm{I}_{9 / 2}\right.$,

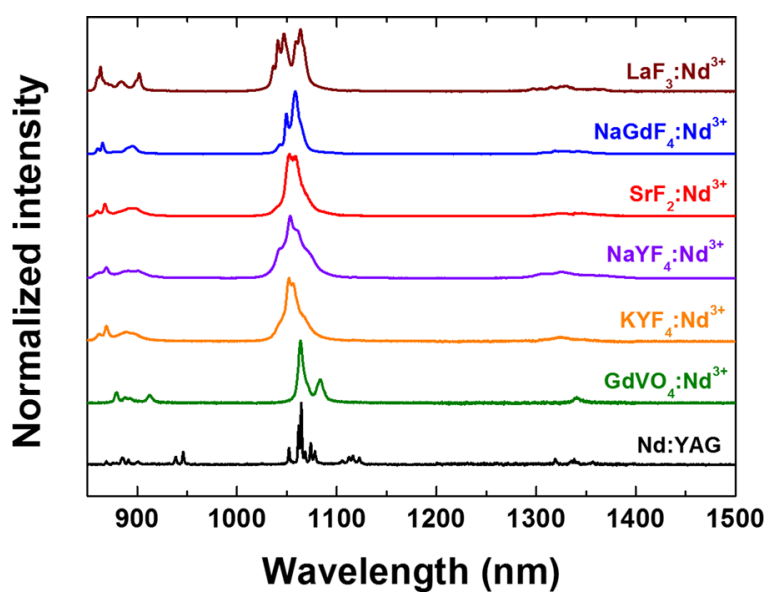

FIG. 7. Normalized emission spectra in the $850-1500 \mathrm{~nm}$ range of the different Nd:NPs studied in this work. In all cases, the excitation wavelength was set to that which maximized the emission intensity at $1060 \mathrm{~nm}$ according to the excitation spectra. 
${ }^{4} \mathrm{~F}_{3 / 2} \rightarrow{ }^{4} \mathrm{I}_{11 / 2}$, and ${ }^{4} \mathrm{~F}_{3 / 2} \rightarrow{ }^{4} \mathrm{I}_{13 / 2}$, respectively) generated from the metastable ${ }^{4} \mathrm{~F}_{3 / 2}$ state of $\mathrm{Nd}^{3+}$ ions. The luminescence band corresponding to the ${ }^{4} \mathrm{~F}_{3 / 2} \rightarrow{ }^{4} \mathrm{I}_{15 / 2}$ transitions lies out of the detection range of our spectrometer so it has not been consider in following discussion/calculations. Nevertheless, it is known that the branching ratio corresponding to this transition is below $1 \%$ so it can be neglected without affecting the validity of our conclusions.

The collected luminescence spectra were used to experimentally determine the branching ratios, $\beta_{\mathrm{j}}$ of the three above mentioned transitions by calculating the integrated intensity of each band. Results are listed in Table II. Among all the materials studied in this work, Nd:YAG is very, likely, the most widely studied in its "bulk" form. According to previous papers reporting on the fluorescence properties of Nd:YAG crystals, the $\beta_{\mathrm{j}}$ values of branching ratios can be estimated to be close to 25,61 , and 14 for $J=9 / 2,11 / 2$, and 13/2, respectively. ${ }^{46,47}$ These values can now be compared to the branching ratios obtained for nanosized Nd:YAG included in Table II. The differences between these two sets of branching ratios are estimated, on average, close to $15 \%$. Although the origin of these differences are out of the scope of this work and their complete understanding would require additional measurements, we state that they are, very likely, due to the wavelength dependence of medium absorption and/or the different groups/molecules coupled to the surface of NPs.

As mentioned in the introduction, although the three emission bands of $\mathrm{Nd}^{3+}$ ions lie in the biological windows, each of them is especially suitable for certain applications. The first emission band, centered at around 890, allows for imaging in the first biological window using a conventional $\mathrm{Si}$ camera. This is particularly interesting when it is not possible to use a camera with enhanced sensitivity in the $1000-1500 \mathrm{~nm}$ infrared spectral range. This band has also been reported to be temperature-sensitive in certain Nd:NPs (Nd:YAG, $\mathrm{NaYF}_{4}: \mathrm{Nd}^{3+}$, and $\mathrm{LaF}_{3}: \mathrm{Nd}^{3+}$ ). ${ }^{34,40,48}$

According to Table II, if fluorescence imaging contrast is to be obtained by using the ${ }^{4} \mathrm{~F}_{3 / 2} \rightarrow{ }^{4} \mathrm{I}_{9 / 2}$ emission line at around $890 \mathrm{~nm}$, the most interesting systems to work with in the first biological window are $\mathrm{KYF}_{4}: \mathrm{Nd}^{3+}$ and $\mathrm{GdVO}_{4}: \mathrm{Nd}^{3+}$ (over $20 \%$ of their total fluorescence signal corresponds to the ${ }^{4} \mathrm{~F}_{3 / 2} \rightarrow{ }^{4} \mathrm{I}_{9 / 2}$ transition). As explained in Sec. III A, none of these systems presents a great degree of instability under small fluctuations in the temperature of the excitation laser

TABLE II. Branching ratios $\beta_{\mathrm{J}, 9 / 2}, \beta_{\mathrm{J}, 11 / 2}$, and $\beta_{\mathrm{J}, 13 / 2}$ corresponding to the ${ }^{4} \mathrm{~F}_{3 / 2} \rightarrow{ }^{4} \mathrm{I}_{9 / 2}$ (890 nm band), ${ }^{4} \mathrm{~F}_{3 / 2} \rightarrow{ }^{4} \mathrm{I}_{11 / 2}$ (1060 nm band), and ${ }^{4} \mathrm{~F}_{3 / 2} \rightarrow{ }^{4} \mathrm{I}_{15 / 2}$ (1320 $\mathrm{nm}$ band) transitions, respectively. The ratios are expressed as percent value of the overall fluorescence emission.

\begin{tabular}{|c|c|c|c|}
\hline Nanoparticle & $\beta_{\mathrm{J}, 9 / 2}(\%)$ & $\beta_{\mathrm{J}, 11 / 2}(\%)$ & $\beta_{\mathrm{J}, 13 / 2}(\%)$ \\
\hline $\mathrm{LaF}_{3}: \mathrm{Nd}^{3+}$ & 18.7 & 73.3 & 8.0 \\
\hline $\mathrm{NaGdF}_{4}: \mathrm{Nd}^{3+}$ & 16.2 & 74.6 & 9.2 \\
\hline $\mathrm{SrF}_{2}: \mathrm{Nd}^{3+}$ & 16.1 & 75.4 & 8.5 \\
\hline $\mathrm{NaYF}_{4}: \mathrm{Nd}^{3+}$ & 15.4 & 71.0 & 13.6 \\
\hline $\mathrm{KYF}_{4}: \mathrm{Nd}^{3+}$ & 20.3 & 69.3 & 10.4 \\
\hline $\mathrm{GdVO}_{4}: \mathrm{Nd}^{3+}$ & 20.9 & 76.9 & 2.2 \\
\hline Nd:YAG & 19.4 & 68.9 & 19.6 \\
\hline
\end{tabular}

diode so they become especially suitable for fluorescence imaging experiments in the first biological window.

Even though it is possible to obtain in vivo images of Nd:NPs using conventional Si cameras, their sensitivity drastically drops for wavelengths longer than $1000 \mathrm{~nm}$. For fluorescence bioimaging in the second biological window, AsGaIn cameras are required. When using these type of cameras, with maximum sensitivity in the $1000-1500 \mathrm{~nm}$ spectral range, the most suitable nanoparticles for bioimaging applications would be those with lower $\beta_{\mathrm{J}, 9 / 2}$ branching ratios (i.e., less intense emission in the first biological window and more intense emission in the second). From the data given in Table II, we can conclude that $\mathrm{NaYF}_{4}: \mathrm{Nd}^{3+}$ is the system that best satisfies this requirement, although the emission in that wavelength range is above $79 \%$ of the total emission intensity for all the systems.

However, when recording in vivo fluorescence images in the infrared, the intrinsic fluorescence of tissues must be considered. A control experiment should be performed beforehand in order to determine if there is a significant autofluorescence background that constitutes a problem for the experiment. If that is the case, according to recently published works, autofluorescence removal requires the use of emission wavelengths longer than $1100 \mathrm{~nm}^{36}$ When working with Nd:NPs, this requirements implies to use only the $1.3 \mu \mathrm{m}$ emission band for fluorescence contrast. Therefore, obtaining autofluorescencefree images of biological systems requires the use of NPs with large values of $\beta_{\mathrm{J}, 13 / 2}$. According to Table II, only three systems (Nd:YAG, $\mathrm{NaYF}_{4}: \mathrm{Nd}^{3+}$, and $\mathrm{KYF}_{4}: \mathrm{Nd}^{3+}$ ) show branching ratios $\beta_{\mathrm{J}, 13 / 2}$ above $10 \%$. Of these three, Nd:YAG NPs are the best candidates, since almost $20 \%$ of the total intensity corresponds to the $1320 \mathrm{~nm}$ transition. However, the narrow emission bands and great size dispersion presented by Nd:YAG NPs must be taken into account before deeming them appropriate for a specific application.

\section{Fluorescence lifetimes}

In Secs. III A and III B, the emission and excitation properties of the different systems have been compared. In a first order approximation, these differences are caused by the structural properties of the host material. Other properties, such as fluorescence lifetime and quantum yield of the emitting level, do not depend only on the host material but also on other parameters related with the large surface-to-volume ratio that characterizes nanosized materials. For luminescent nanoparticles, surface plays a relevant role in the luminescence dynamics through the presence of surface defects and non-radiative interaction with ligands and medium. As a consequence, the fluorescence lifetimes of Nd:NPs are strongly dependent on the surface treatment and quality.

The fluorescence lifetimes reported in this section correspond to those as obtained from colloidal dispersions of the as-synthesized used in this work. Figure 8 shows the fluorescence decay curves of the ${ }^{4} \mathrm{~F}_{3 / 2}$ energy level as obtained for all the Nd:NPs here studied, which were recorded at a emission wavelength of $890 \mathrm{~nm}$. All the decay curves have been found to follow a non-exponential trend, whose exact origin should be determined performing a deep analysis in each 


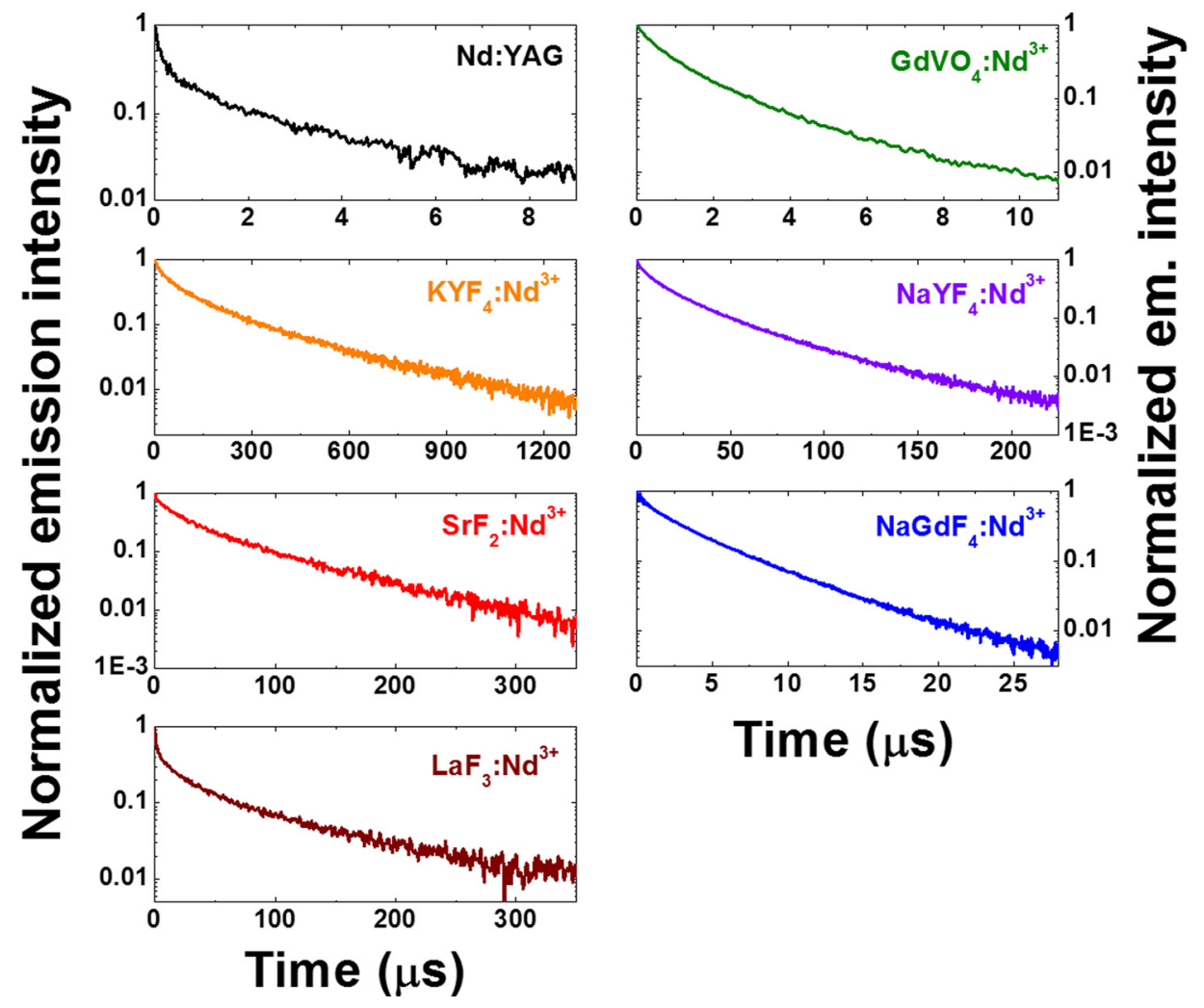

FIG. 8. Fluorescence decay curves of the ${ }^{4} \mathrm{~F}_{3 / 2}$ level of $\mathrm{Nd}^{3+}$ ions for all the different systems studied in this work. All the curves were recorded at $890 \mathrm{~nm}$ and correspond to those obtained for aqueous dispersions of the nanoparticles.

case (out of the scope of this work). However, the nonexponential nature of the curves is very likely due to the presence of energy transfer processes inside the nanoparticle between $\mathrm{Nd}^{3+}$ ions or between $\mathrm{Nd}^{3+}$ ions and acceptors such as defects in the crystal structure or $\mathrm{OH}$ groups in the volume of the NPs as demonstrated in previous works. Due to the non-exponential character of decay curves, the average fluorescence lifetime, $\tau$, has been defined as

$$
\tilde{\tau}=\int t \cdot I(t) d t / \int I(t) d t,
$$

being $I(t)$ the fluorescence intensity at time $t$ measured from laser pulse, has been calculated. The obtained values for the average fluorescence lifetime are listed in Table III. As shown, the lifetime values of the as-synthesized systems greatly vary from one system to another, ranging from less than $1 \mu \mathrm{s}(\mathrm{Nd}: \mathrm{YAG})$ to more than $100 \mu \mathrm{s}\left(\mathrm{KYF}_{4}: \mathrm{Nd}^{3+}\right)$.

As mentioned before, for each specific crystal matrix, the fluorescence lifetime is expected to depend on the $\mathrm{Nd}^{3+}$

TABLE III. Average fluorescence lifetimes of the ${ }^{4} \mathrm{~F}_{3 / 2}$ level of the Nd:NPs studied in this work, as obtained for aqueous dispersions of each of the nanoparticles.

\begin{tabular}{|c|c|}
\hline Nanoparticle & Average fluorescence lifetime, $\tilde{\tau}(\mu \mathrm{s})$ \\
\hline $\mathrm{LaF}_{3}: \mathrm{Nd}^{3+}$ & 26.39 \\
\hline $\mathrm{NaGdF}_{4}: \mathrm{Nd}^{3+}$ & 3.12 \\
\hline $\mathrm{SrF}_{2}: \mathrm{Nd}^{3+}$ & 35.36 \\
\hline $\mathrm{NaYF}_{4}: \mathrm{Nd}^{3+}$ & 19.03 \\
\hline $\mathrm{KYF}_{4}: \mathrm{Nd}^{3+}$ & 123.03 \\
\hline $\mathrm{GdVO}_{4}: \mathrm{Nd}^{3+}$ & 1.5 \\
\hline Nd:YAG & 0.84 \\
\hline
\end{tabular}

doping level: higher doping levels result in concentration induced quenching, i.e., in lower lifetime values. Along with concentration quenching, other factors such as surface hydroxyls $(-\mathrm{OH})$ and defects in the volume like mesopores filled by the $-\mathrm{OH}$ groups are responsible for nonradiative losses in rare earth-doped materials which lead to reduced fluorescence lifetimes. ${ }^{49-52}$ Since neither $\mathrm{Nd}^{3+}$ concentrations nor surface treatments are the same in all the Nd:NPs studied in this work, the average lifetime values given in Table III do not constitute a general comparison table but rather a comparison of the fluorescence lifetimes of assynthesized Nd:NPs. Despite it cannot be considered as a general comparison table, some general trend can be extracted from data included in Table III. In particular, the low lifetime values observed for $\mathrm{GdVO}_{4}: \mathrm{Nd}^{3+}$ and $\mathrm{Nd}: \mathrm{YAG}$ could also be explained taking into account that oxides present much larger phonon energies than fluorides, which results in greater nonradiative losses. ${ }^{53}$

\section{CONCLUSIONS}

The spectroscopic properties of different Neodymiumdoped nanoparticles have been systematically analyzed and compared in order to discuss their possible application in infrared fluorescence in vivo imaging experiments. The comparison between their spectroscopic properties has revealed that, although all these nanoparticles can be excited with an $808 \mathrm{~nm}$ laser diode and present emission bands in the first and second biological windows, there are remarkable differences in their fluorescence properties. Both the optimum excitation wavelength (which has been found to vary between about $788 \mathrm{~nm}$ and $809 \mathrm{~nm}$ ) and the width of the excitation band (which determines the absorption efficiency and 
stability of the fluorescence signal) have been found to be greatly dependent on the crystal host. In this respect, $\mathrm{GdVO}_{4}: \mathrm{Nd}^{3+}$ nanoparticles have emerged as specially interesting as they show a similar excitation band (in terms of spectral width and central wavelength) to the emission spectrum of $808 \mathrm{~nm}$ emitting commercial laser diodes (typically employed as excitation sources in small animal fluorescence imaging systems).

In addition, the comparison between the emission spectra has revealed significant variations of the fluorescence branching ratios from system to system, this determining the suitability of each Nd:NP for specific applications. As an example, $\mathrm{GdVO}_{4}: \mathrm{Nd}^{3+} \mathrm{NPs}$ have been revealed as optimum infrared emitting probes for in vivo imaging in the first biological window by using commercial $\mathrm{Si}$ cameras. On the other hand, $\mathrm{NaYF}_{4}: \mathrm{Nd}^{3+}$ and $\mathrm{Nd}: \mathrm{YAG}$ nanoparticles show the highest ${ }^{4} \mathrm{~F}_{3 / 2} \rightarrow{ }^{4} \mathrm{I}_{13 / 2}$ branching ratio and, thus, emerge as promising luminescent probes for in vivo autofluorescencefree infrared imaging.

All the information provided throughout this comprehensive study will allow the fluorescence NIR-imaging community to choose the most appropriate nanoparticle for each specific application depending on the experiment and detection system available, thus greatly increasing the possibilities of an impactful outcome.

\section{ACKNOWLEDGMENTS}

This project has been supported by the Spanish Ministerio de Economía y Competitividad under Project No. MAT201347395-C4-1-R. B. del Rosal thanks Universidad Autónoma de Madrid for an FPI grant. M. Misiak and A. Bednarkiewicz acknowledge the support from POIG.01.01.02-02-002/08 project financed by the European Regional Development Fund (Operational Programme Innovative Economy, 1.1.2). Yu. Orlovskii and A. Vanetsev acknowledge the support from the Centre of Excellence TK114 "Mesosystems: Theory and Applications"; TK117 "High-Technology Materials for Sustainable Development" and European Social Fund, Project No. \#MTT50. Dragana Jovanović and Miroslav Dramićanin acknowledge financial support of the Ministry of Education, Science and Technological development of the Republic of Serbia (Grant No. 45020). The authors are grateful to G. Dražić for TEM measurements of $\mathrm{GdVO}_{4}$ nanoparticles. The authors also thank the Brazilian agencies FAPEAL-Fundação de Amparo a Pesquisa do Estado de Alagoas (Project No. PRONEX 2009-09-006), FINEP (Financiadora de Estudos e Projetos), CNPq (Conselho Nacional de Desenvolvimento Científico e Tecnológico) through Grant INCT NANO(BIO)SIMES, and D. Jaque (Pesquisador Visitante Especial (PVE)-CAPES) thanks CAPES (Coordenadoria de Aperfeiçoamento de Pessoal de Ensino Superior) for the Project PVE No. A077/2013. K.U.K. is a Postdoctoral fellow of the Project PVE A077/2013. E. Navarro is funded by National Council for Science and Technology in México CONACyT (Scholarship Ref. No. 207858/2014). Partial support from DGAPA-UNAM (Grant No. 109913) was gratefully acknowledged. A. S. and M. P. gratefully acknowledge Fondazione Cariverona (Verona, Italy) for financial support in the framework of the "Verona Nanomedicine Initiative".

${ }^{1}$ D. W. Hedley, M. L. Friedlander, I. W. Taylor, C. A. Rugg, and E. A. Musgrove, J. Histochem. Cytochem. 31(11), 1333-1335 (1983).

${ }^{2}$ F. W. Rost, Fluorescence Microscopy (Cambridge University Press, 1995).

${ }^{3}$ C. Xu, W. Zipfel, J. B. Shear, R. M. Williams, and W. W. Webb, Proc. Natl. Acad. Sci. U. S. A. 93(20), 10763-10768 (1996).

${ }^{4}$ G. A. Wagnieres, W. M. Star, and B. C. Wilson, Photochem. Photobiol. 68(5), 603-632 (1998).

${ }^{5}$ J. H. Rao, A. Dragulescu-Andrasi, and H. Q. Yao, Curr. Opin. Biotechnol. 18(1), 17-25 (2007).

${ }^{6}$ N. Tagaya, R. Yamazaki, A. Nakagawa, A. Abe, K. Hamada, K. Kubota, and T. Oyama, Am. J. Surg. 195(6), 850-853 (2008).

${ }^{7}$ W. Stummer, U. Pichlmeier, T. Meinel, O. D. Wiestler, F. Zanella, H.-J. Reulen, and A.-G. S. Group, Lancet Oncol. 7(5), 392-401 (2006).

${ }^{8}$ G. M. van Dam, G. Themelis, L. M. Crane, N. J. Harlaar, R. G. Pleijhuis, W. Kelder, A. Sarantopoulos, J. S. de Jong, H. J. Arts, and A. G. van der Zee, Nat. Med. 17(10), 1315-1319 (2011).

${ }^{9}$ A. Nakayama, F. del Monte, R. J. Hajjar, and J. V. Frangioni, Mol. Imaging 1(4), 365-377 (2002).

${ }^{10}$ M. Sekijima, T. Tojimbara, S. Sato, M. Nakamura, T. Kawase, K. Kai, Y. Urashima, I. Nakajima, S. Fuchinoue, and S. Teraoka, Presented at the Transplantation Proceedings (2004).

${ }^{11}$ E. Carrasco, B. del Rosal, F. Sanz-Rodríguez, Á. J. de la Fuente, P. H. Gonzalez, U. Rocha, K. U. Kumar, C. Jacinto, J. G. Solé, and D. Jaque, Adv. Funct. Mater. 25(4), 615-626 (2015).

${ }^{12}$ J. V. Frangioni, Curr. Opin. Chem. Biol. 7(5), 626-634 (2003).

${ }^{13}$ S. Andersson-Engels, C. A. Klinteberg, K. Svanberg, and S. Svanberg, Phys. Med. Biol. 42(5), 815 (1997).

${ }^{14}$ E. A. te Velde, T. Veerman, V. Subramaniam, and T. Ruers, Eur. J. Surg. Oncol. 36(1), 6-15 (2010).

${ }^{15}$ P. Sharma, S. Brown, G. Walter, S. Santra, and B. Moudgil, Adv. Colloid Interface Sci. 123-126, 471-485 (2006).

${ }^{16}$ U. Resch-Genger, M. Grabolle, S. Cavaliere-Jaricot, R. Nitschke, and T. Nann, Nat. Methods 5(9), 763-775 (2008).

${ }^{17}$ D. Jaque, L. M. Maestro, B. del Rosal, P. Haro-Gonzalez, A. Benayas, J. L. Plaza, E. M. Rodriguez, and J. G. Sole, Nanoscale 6(16), 9494-9530 (2014).

${ }^{18}$ X. H. Gao, Y. Y. Cui, R. M. Levenson, L. W. K. Chung, and S. M. Nie, Nat. Biotechnol. 22(8), 969-976 (2004).

${ }^{19}$ D. R. Larson, W. R. Zipfel, R. M. Williams, S. W. Clark, M. P. Bruchez, F. W. Wise, and W. W. Webb, Science 300(5624), 1434-1436 (2003).

${ }^{20}$ M. F. Tsai, S. H. Chang, F. Y. Cheng, V. Shanmugam, Y. S. Cheng, C. H. Su, and C. S. Yeh, ACS Nano 7(6), 5330-5342 (2013).

${ }^{21}$ S.-T. Yang, L. Cao, P. G. Luo, F. Lu, X. Wang, H. Wang, M. J. Meziani, Y. Liu, G. Qi, and Y.-P. Sun, J. Am. Chem. Soc. 131(32), 11308-11309 (2009).

${ }^{22}$ K. Welsher, S. P. Sherlock, and H. Dai, Proc. Natl. Acad. Sci. U. S. A. 108(22), 8943-8948 (2011).

${ }^{23}$ Q. Zhao, K. Li, S. Chen, A. Qin, D. Ding, S. Zhang, Y. Liu, B. Liu, J. Z. Sun, and B. Z. Tang, J. Mater. Chem. 22(30), 15128-15135 (2012).

${ }^{24}$ R. Kumar, M. Nyk, T. Y. Ohulchanskyy, C. A. Flask, and P. N. Prasad, Adv. Funct. Mater. 19(6), 853-859 (2009).

${ }^{25}$ A. M. Smith, M. C. Mancini, and S. Nie, Nat. Nanotechnol. 4(11), 710-711 (2009).

${ }^{26}$ R. Weissleder, Nat. Biotechnol. 19(4), 316-317 (2001).

${ }^{27}$ S. Stolik, J. Delgado, A. Perez, and L. Anasagasti, J. Photochem. Photobiol. B: Biol. 57(2), 90-93 (2000).

${ }^{28}$ J. Zhou, Y. Sun, X. Du, L. Xiong, H. Hu, and F. Li, Biomaterials 31(12), 3287-3295 (2010).

${ }^{29}$ J. T. Robinson, G. Hong, Y. Liang, B. Zhang, O. K. Yaghi, and H. Dai, J. Am. Chem. Soc. 134(25), 10664-10669 (2012).

${ }^{30}$ G. Chen, J. Shen, T. Y. Ohulchanskyy, N. J. Patel, A. Kutikov, Z. Li, J. Song, R. K. Pandey, H. Ågren, and P. N. Prasad, ACS Nano 6(9), 8280-8287 (2012).

${ }^{31}$ L. M. Maestro, P. Haro-Gonzalez, B. del Rosal, J. Ramiro, A. J. Caamano, E. Carrasco, A. Juarranz, F. Sanz-Rodriguez, J. G. Sole, and D. Jaque, Nanoscale 5(17), 7882-7889 (2013).

${ }^{32}$ G. H. Dieke, H. M. Crosswhite, and H. Crosswhite, Spectra and Energy Levels of Rare Earth Ions in Crystals (Interscience Publishers, New York, 1968). 
${ }^{33}$ G. Chen, T. Y. Ohulchanskyy, S. Liu, W.-C. Law, F. Wu, M. T. Swihart, H. Ågren, and P. N. Prasad, ACS Nano 6(4), 2969-2977 (2012).

${ }^{34}$ U. Rocha, C. Jacinto da Silva, W. Ferreira Silva, I. Guedes, A. Benayas, L. Martínez Maestro, M. Acosta Elias, E. Bovero, F. C. J. M. van Veggel, J. A. García Solé, and D. Jaque, ACS Nano 7(2), 1188-1199 (2013).

${ }^{35}$ U. Rocha, K. U. Kumar, C. Jacinto, I. Villa, F. Sanz-Rodríguez, M. del Carmen Iglesias de la Cruz, A. Juarranz, E. Carrasco, F. C. J. M. van Veggel, E. Bovero, J. G. Solé, and D. Jaque, Small 10(6), 1141-1154 (2014).

${ }^{36}$ I. Villa, A. Vedda, I. X. Cantarelli, M. Pedroni, F. Piccinelli, M. Bettinelli, A. Speghini, M. Quintanilla, F. Vetrone, U. Rocha, C. Jacinto, E. Carrasco, F. Rodríguez, Á. Juarranz, B. del Rosal, D. Ortgies, P. Gonzalez, J. Solé, and D. García, Nano Res. 8(2), 649-665 (2015).

${ }^{37}$ A. Bednarkiewicz, D. Wawrzynczyk, M. Nyk, and W. Strek, Appl. Phys. B, Lasers Opt. 103(4), 847-852 (2011).

${ }^{38}$ E. Samsonova, A. Popov, A. Vanetsev, K. Keevend, K. Kaldvee, L. Puust, A. Baranchikov, A. Ryabova, S. Fedorenko, and V. Kiisk, "Fluorescence quenching mechanism for water-dispersible $\mathrm{Nd}^{3+}: \mathrm{KYF}_{4}$ nanoparticles synthesized by microwave-hydrothermal technique," J. Lumin. (published online).

${ }^{39}$ T. V. Gavrilović, D. J. Jovanović, V. Lojpur, and M. D. Dramićanin, Sci. Rep. 4, 4209 (2014).

${ }^{40}$ A. Benayas, B. del Rosal, A. Pérez-Delgado, K. Santacruz-Gómez, D. Jaque, G. A. Hirata, and F. Vetrone, Adv. Opt. Mater. 3(5), 687-694 (2015).

${ }^{41}$ M. Pedroni, F. Piccinelli, T. Passuello, M. Giarola, G. Mariotto, S. Polizzi, M. Bettinelli, and A. Speghini, Nanoscale 3(4), 1456-1460 (2011).
${ }^{42}$ M. Wang, J.-L. Liu, Y.-X. Zhang, W. Hou, X.-L. Wu, and S.-K. Xu, Mater. Lett. 63(2), 325-327 (2009).

${ }^{43}$ H. Liang, K. T. Vu, P. Krishnan, T. C. Trang, D. Shin, S. Kimel, and M. W. Berns, Biophys. J. 70(3), 1529 (1996).

${ }^{44}$ K. König, H. Liang, M. W. Berns, and B. J. Tromberg, Opt. Lett. 21(14), 1090-1092 (1996).

${ }^{45}$ J. Bartla, R. Fírab, and V. Jackoa, Meas. Sci. Rev. 2(3), 9-15 (2002).

${ }^{46}$ T. Kushida, H. Marcos, and J. Geusic, Phys. Rev. 167(2), 289 (1968).

${ }^{47}$ G. W. Burdick, C. Jayasankar, F. Richardson, and M. F. Reid, Phys. Rev. B 50(22), 16309 (1994).

${ }^{48}$ D. Wawrzynczyk, A. Bednarkiewicz, M. Nyk, W. Strek, and M. Samoc, Nanoscale 4(22), 6959-6961 (2012).

${ }^{49}$ E. V. Samsonova, A. V. Popov, A. S. Vanetsev, K. Keevend, E. O. Orlovskaya, V. Kiisk, S. Lange, U. Joost, K. Kaldvee, U. Mäeorg, N. A. Glushkov, A. V. Ryabova, I. Sildos, V. V. Osiko, R. Steiner, V. B. Loschenov, and Y. V. Orlovskii, Phys. Chem. Chem. Phys. 16(48), 26806-26815 (2014).

${ }^{50}$ G. A. Kumar, C. W. Chen, J. Ballato, and R. E. Riman, Chem. Mater. 19, 1523-1528 (2007).

${ }^{51}$ W. D. Horrocks and D. R. Sudnick, J. Am. Chem. Soc. 101(2), 334-340 (1979).

${ }^{52}$ Y. V. Orlovskii, A. Popov, V. Platonov, S. Fedorenko, I. Sildos, and V. Osipov, J. Lumin. 139, 91-97 (2013).

${ }^{53}$ S. Tanabe, H. Hayashi, T. Hanada, and N. Onodera, Opt. Mater. 19(3), 343-349 (2002). 